Journal of Physical Activity and Health, 2012, 9,
(c) 2012 Human Kinetics, Inc.

\title{
Validation of Secondary Commercial Data Sources for Physical Activity Facilities in Urban and Nonurban Settings
}

\author{
Euna Han, Lisa Powell, Sandy Slater, and Christopher Quinn
}

\begin{abstract}
Background: Secondary data are often necessary to assess the availability of commercial physical activity (PA) facilities and examine its association with individual behaviors and outcomes, yet the validity of such sources has been explored only in a limited number of studies. Methods: Field data were collected on the presence and attributes of commercial PA facilities in a random sample of 30 urban, 15 suburban, and 15 rural Census tracts in the Chicago metropolitan statistical area and surrounding area. Results: Approximately $40 \%$ of PA establishments in the field data were listed for both urban and nonurban tracts in both lists except for nonurban tracts in D\&B (35\%), which was significantly improved in the combined list of D\&B and InfoUSA. Approximately one-quarter of the PA facilities listed in D\&B were found on the ground, whereas $40 \%$ to $50 \%$ of PA facilities listed in InfoUSA were found on the ground. PA establishments that offered instruction programs or lessons or that had a court or pool were less likely to be listed, particularly in the nonurban tracts. Conclusions: Secondary commercial business lists on PA facilities should be used with caution in assessing the built environment.
\end{abstract}

Keywords: validation, Dun \& Bradstreet, InfoUSA, physical activity establishments

As the prevalence of obesity increased dramatically in the United States over the past few decades, researchers have explored neighborhood contextual environments as key modifiable factors to combat this epidemic. ${ }^{1,2} \mathrm{~A}$ number of recent studies explored the extent to which access to physical activity (PA) facilities was associated with PA-related behavior and individual body weight outcomes, particularly among youths. Previous literature reported a positive association of public and/or commercial local area PA facility availability with the level of PA. ${ }^{3-7}$ In addition, perceived availability of PA facilities was associated with higher levels of PA among middleand high-school aged children. ${ }^{8,9} \mathrm{PA}$ also was reported to have a statistically significant association with obesity prevalence among youths. ${ }^{3,10-12}$

Previous studies measured variations in the built environment, particularly for commercial PA facilities, with a variety of sources including direct field observations and secondary data sources, such as telephone directories and commercial business databases. Although data on PA facilities collected in the field by trained staff can

Han (corresponding author) is with the College of Pharmacy, Gachon University, and Gachon Institute of Pharmaceutical Sciences, Incheon, Republic of Korea. Powell, Slater, and Quinn are with the Institute for Health Research and Policy, University of Illinois at Chicago. be considered as the "gold standard," it is time intensive, costly, often focuses on a specific geographic area, and cannot be easily linked to existing national longitudinal or historical cross-sectional, individual-level data. Therefore, researchers often tend to rely on secondary data for studies examining the relationship of environmental factors for PA and individual behavioral or weight outcomes. Despite such dependence on secondary data sources, limited validation on commercial business lists of PA establishments with on the ground direct observations has been undertaken in the previous literature.

We could locate only a few previous studies that validated existing secondary data for the PA environment, 1 in Canada and 2 in the United States. ${ }^{13-15}$ These studies overall reported poor to moderate levels of validity for the secondary sources of PA facilities. Our study built on the previous studies and validated PA facility data from the 2 most widely available U.S. commercial business lists, Dun \& Bradstreet (D\&B) and InfoUSA, in the ChicagoJoliet-Naperville, IL-IN-WI Metropolitan Statistical Area (Chicago MSA) and surrounding nonurban areas. Our study was the first to assess the validity of PA facilities for both D\&B and InfoUSA using direct field observations. We examined the level of agreement between direct field observations and information in each of the 2 secondary commercial business lists. We also used the combination of those 2 sources to assess the advantage of using combined sources. Further building on the previous literature, we collected characteristics from the interior 
of each PA facility and reported whether any statistically significant differences were found in those characteristics by validation status.

\section{Methods}

\section{Data}

As part of a larger food outlet validation study, ${ }^{16} \mathrm{sec}$ ondary commercial business list data on commercial PA facilities were drawn from D\&B and InfoUSA and were validated with direct field observations based on a random sample of 30 urban census tracts from the Chicago MSA and a random sample of 15 suburban and 15 rural census tracts from a 50-mile buffer surrounding the Chicago MSA.

The 60 census tracts represented 1472 square miles (53 and 1419 square miles in the urban and nonurban tracts, respectively) and covered approximately 5076 total road miles ( 578 and 4498 miles in the urban and nonurban tracts, respectively).

Field observations were conducted from May 2009 through July 2009 . Observers received 24 hours of training on the content of the data collection instruments and procedures for conducting observations including the use of maps. Observers were instructed to observe all streets within each tract as shown on the maps. Two trained field staff surveyed each census tract by walking or driving all streets contained within the tract to 1) identify any commercial PA facilities and 2) collect the presence of specific attributes inside the premises of such facilities. For each facility, data were collected on the following specific attributes: whether they charged a fee, required membership, offered instruction programs or lessons, had multiple cardiovascular and strength training equipment, had a multipurpose room, had a gymnasium, had a playing court, or had a pool. A total of 54 and 52 PA facilities were identified on the ground in the urban and nonurban tracts, respectively.

We obtained commercial data on PA facilities from D\&B and InfoUSA with a reference date of May 2009. We used data on establishments with primary or secondary PA facility-related Standard Industrial Classification (SIC) codes for both D\&B (8-digit) and InfoUSA (6-digit; see Table 1 for a full list of SIC codes).

All establishments in the lists were geocoded at the roof top level (the polygon centroid of a known building footprint) or street address maintained in the ArcGIS Online Geocoding Task using ArcGIS 9.1. Because our geographic sampling unit was the census tract, the remaining outlets that could only be geocoded less accurately than at the roof top or street address to the centroid of the zip code were not eligible for inclusion in our study. The geocoded locations were then matched to the census tracts using ArcGIS. We also generated a combined list of D\&B and InfoUSA by manually dropping duplicated facilities by name, address, and phone number between the 2 business lists. A total of 155, 94, and 192 PA facilities were listed in D\&B, InfoUSA, and the combined list, respectively, for our sample census tracts.

\section{Analyses}

The validity of the 2 secondary commercial business lists and the combined list was assessed by 3 validity indices, including 1) Sensitivity: the proportion of establishments observed on the ground that was listed in the commercial databases; 2) Positive Predictive Value (PPV): the proportion of establishments listed in the commercial databases that was observed on the ground; and 3) Concordance: the proportion of listed PA facilities also verified on the ground among those that were either found on the ground or in the business lists. Standard errors were calculated for all indices. We used Fisher's Exact test (2-sided $p$ ) to test for significant differences in the validity indices by urbanicity and by commercial business type within each urbanicity.

For PA facilities found on the ground, we compared attributes of each facility by whether it was found in a business list. A 2-sided $t$ test was performed to determine whether any statistically significant differences existed in the characteristics of those facilities listed in a business list versus those not listed. We also examined the distribution of primary SIC codes for PA facilities that were listed but not found on the ground and we reviewed the primary SIC codes to identify whether there were particular patterns of mismatch.

\section{Results}

Table 2 presents the validity statistics by business list and urbanicity. We found a total of 54 and 52 PA facilities on the ground in urban and nonurban tracts, respectively, whereas 77 and 78 PA facilities for D\&B and 42 and 52 PA facilities for InfoUSA were listed in urban and nonurban tracts, respectively.

Sensitivity was $41 \%$ in urban tracts and $35 \%$ in nonurban tracts in D\&B. Similarly in InfoUSA, sensitivity was higher in urban tracts at $39 \%$, whereas the sensitivity in nonurban tracts was $40 \%$. Combining the 2 commercial business lists largely improved the sensitivity across all tracts, which climbed to $52 \%$ in both the urban and nonurban tracts, respectively. The increase in the sensitivity for the urban tracts in the combined list was statistically significant compared with both D\&B and InfoUSA. The differences in sensitivity between the urban and nonurban tracts were not statistically significantly different for D\&B and InfoUSA, or the combined list.

Positive predictive value (PPV), the proportion of outlets listed that were observed in the field, was fair in both lists. PPV in urban compared with nonurban tracts was $29 \%$ versus $23 \%$ in $\mathrm{D} \& \mathrm{~B}$ and $50 \%$ versus $40 \%$ in InfoUSA. PPV in the combined list in the urban tracts was $30 \%$, whereas it was $27 \%$ in nonurban tracts. For each of the business lists and the combined list, the differences by urbanicity were not statistically significant. 
Table 1 List of Standard Industrial Classification (SIC) Code for PA-Related Facilities

\begin{tabular}{|c|c|}
\hline \multicolumn{2}{|c|}{ D\&B (8-digits of Primary and Secondary SIC code) } \\
\hline 79110000 & Dance studios, schools, and halls \\
\hline 79110100 & Dance hall services \\
\hline 79110101 & Dance hall or ballroom operation \\
\hline 79110102 & $\begin{array}{l}\text { Discotheque, except those serving alcoholic } \\
\text { beverages }\end{array}$ \\
\hline 79110200 & Dance instructor and school services \\
\hline 79110201 & Children's dancing school \\
\hline 79110202 & Dance instructor \\
\hline 79110203 & Dance studio and school \\
\hline 79110204 & Professional dancing school \\
\hline 79330000 & Bowling centers \\
\hline 79339900 & Bowling centers, nec \\
\hline 79339901 & Candle pin center \\
\hline 79339902 & Duck pin center \\
\hline 79339903 & Ten pin center \\
\hline 79910000 & Physical fitness facilities \\
\hline 79910100 & $\begin{array}{l}\text { Physical fitness clubs with training } \\
\text { equipment }\end{array}$ \\
\hline 79910101 & Athletic club and gymnasiums, membership \\
\hline 79910102 & Health club \\
\hline 79910103 & Spas \\
\hline 79910200 & Weight reducing clubs \\
\hline 79910201 & Reducing facility \\
\hline 79910202 & Slenderizing salon \\
\hline 79910300 & Exercise facilities \\
\hline 79910301 & Aerobic dance and exercise classes \\
\hline 79910302 & Exercise salon \\
\hline 79920000 & Public golf courses \\
\hline 79970000 & Membership sports and recreation clubs \\
\hline 79970100 & Ice sports \\
\hline 79970101 & Curling club, membership \\
\hline 79970102 & $\begin{array}{l}\text { Hockey club, except professional } \\
\text { and semiprofessional }\end{array}$ \\
\hline 79970200 & Boating and swimming clubs \\
\hline 79970202 & Boating club, membership \\
\hline 79970203 & Swimming club, membership \\
\hline 79970400 & Outdoor field clubs \\
\hline 79970401 & $\begin{array}{l}\text { Baseball club, except professional } \\
\text { and semiprofessional }\end{array}$ \\
\hline 79970402 & $\begin{array}{l}\text { Football club, except professional } \\
\text { and semiprofessional }\end{array}$ \\
\hline 79970404 & $\begin{array}{l}\text { Soccer club, except professional } \\
\text { and semiprofessional }\end{array}$ \\
\hline 79970500 & Indoor/outdoor court clubs \\
\hline 79970501 & Handball club, membership \\
\hline
\end{tabular}

D\&B (8-digits of Primary and Secondary SIC code)

79970502 Racquetball club, membership

79970503 Squash club, membership

79970504 Tennis club, membership

79979902 Bowling league or team

79979904 Country club, membership

79979906 Golf club, membership

79979907 Lawn bowling club, membership

79979908 Riding club, membership

79990100 Tennis services and professionals

79990101 Tennis club, nonmembership

79990102 Tennis courts, outdoor/indoor: nonmembership

79990103 Tennis professional

$79990200 \quad$ Golf services and professionals

79990202 Golf driving range

79990203 Golf professionals

79990204 Golf, pitch-n-putt

79990205 Miniature golf course operation

$79990300 \quad$ Indoor court clubs

79990301 Handball courts, nonmembership

79990302 Racquetball club, nonmembership

79990303 Squash club, nonmembership

$79990600 \quad$ Skating rink operation services

79990601 Curling rinks

79990602 Ice skating rink operation

79990603 Roller skating rink operation

79990700 Shooting facilities and archery lanes

79990701 Archery lanes

79991100 Instruction schools, camps, and services

79991102 Baseball instruction school

79991103 Basketball instruction school

79991104 Bowling instruction

79991107 Diving instruction, underwater

79991108 Games, instruction

79991109 Gymnastic instruction, nonmembership

$79991110 \quad$ Hockey instruction school

79991111 . Judo instruction

79991112 Karate instruction

79991113 Martial arts school, nec

79991115 Sailing instruction

79991116 Scuba and skin diving instruction

79991118 Skating instruction, ice or roller

79991119 Ski instruction 
Table 1 (continued)

\begin{tabular}{|c|c|}
\hline \multicolumn{2}{|c|}{ D\&B (8-digits of Primary and Secondary SIC code) } \\
\hline 79991120 & Sports instruction, schools and camps \\
\hline 79991121 & Surfing instruction \\
\hline 79991122 & Swimming instruction \\
\hline 79991123 & Yoga instruction \\
\hline 79991127 & Physical fitness instruction \\
\hline 79991200 & Riding and rodeo services \\
\hline 79991201 & Riding academy and school \\
\hline 79991202 & Riding stable \\
\hline 79991204 & Rodeo operation \\
\hline 79991412 & Swimming pool, nonmembership \\
\hline 79991512 & Waterslide operation \\
\hline 79991513 & Wave pool operation \\
\hline 79999903 & Baseball batting cage \\
\hline 79999910 & Recreation center \\
\hline 79999912 & Recreation services \\
\hline 79999917 & Trampoline operation \\
\hline \multicolumn{2}{|c|}{ InfoUSA (6-digit of Primary and Secondary SIC code) } \\
\hline 791101 & Dancing instruction \\
\hline 791104 & Hula instruction \\
\hline 793301 & Bowling centers \\
\hline 794102 & Soccer clubs \\
\hline 794103 & Basketball clubs \\
\hline 794105 & Football clubs \\
\hline 794109 & Polo clubs \\
\hline 794110 & Sports-indoor \\
\hline 799101 & Health clubs studios \& gymnasiums \\
\hline 799102 & Gymnasiums \\
\hline 799103 & Aerobic instruction \\
\hline 799105 & Spas (health) \\
\hline 799107 & Pilates \\
\hline 799108 & Children's fitness \\
\hline 799109 & Senior citizen fitness \\
\hline 799110 & Medical fitness centers \\
\hline 799111 & Sports \& recreation facilities program \\
\hline 799201 & Golf courses-public \\
\hline 799202 & Putting greens \\
\hline 799701 & Recreation centers \\
\hline 799702 & Racquetball courts-private \\
\hline 799703 & Tennis courts-private \\
\hline 799704 & Swimming pools-private \\
\hline 799705 & Hockey clubs \\
\hline 799706 & Golf courses-private \\
\hline 799707 & Curling clubs \\
\hline
\end{tabular}






\section{Table 2 Validation Statistics by Business List and Urbanicity}

\begin{tabular}{|c|c|c|c|}
\hline . & & Urban & Nonurban \\
\hline \multirow[t]{8}{*}{$\mathrm{D} \& \mathrm{~B}$} & Ground total & 54 & 52 \\
\hline & List total & 77 & 78 \\
\hline & Sensitivity & $0.407^{\mathrm{b}}$ & 0.346 \\
\hline & & $(0.067)$ & $(0.067)$ \\
\hline & Positive Predictive Value & $0.286^{\mathrm{a}}$ & $0.231^{\mathrm{i}}$ \\
\hline & & $(0.052)$ & $(0.048)$ \\
\hline & Concordance & 0.202 & 0.161 \\
\hline & & $(0.039)$ & $(0.035)$ \\
\hline \multirow[t]{8}{*}{ InfoUSA } & Ground total & 54 & 52 \\
\hline & List total & 42 & 52 \\
\hline & Sensitivity & $0.389^{\mathrm{h}}$ & 0.404 \\
\hline & & $(0.067)$ & $(0.069)$ \\
\hline & Positive Predictive Value & $0.500^{\mathrm{h}}$ & 0.404 \\
\hline & & $(0.078)$ & $(0.069)$ \\
\hline & Concordance & 0.280 & 0.253 \\
\hline & & $(0.052)$ & $(0.048)$ \\
\hline \multirow[t]{8}{*}{ Combined } & Ground total & 54 & 52 \\
\hline & List total & 93 & 99 \\
\hline & Sensitivity & 0.519 & 0.519 \\
\hline & & $(0.069)$ & $(0.070)$ \\
\hline & Positive Predictive Value & 0.301 & 0.273 \\
\hline & & $(0.048)$ & $(0.045)$ \\
\hline & Concordance & 0.235 & 0.218 \\
\hline & & $(0.039)$ & $(0.037)$ \\
\hline
\end{tabular}

Note. Sensitivity represents the proportion of physical activity facilities found on the ground that were listed in a business list. Positive Predictive Value is the proportion of PA facilities listed in a business list that were found on the ground survey. Concordance is the proportion of listed PA facilities also verified on the ground among those that were either found on the ground or in the business lists. Statistical significance denoted at $(P<.05)$ within each characteristic as follows: a significant difference between D\&B and InfoUSA; ${ }^{\mathrm{b}}$ significant difference between individual list (D\&B and InfoUSA) and the combined list.

However, PPV in InfoUSA was statistically significantly higher than PPV in D\&B (for both urban and nonurban tracts) and the combined list (urban tracts only; Table 2).

Finally, we calculated the proportion of listed PA facilities also verified on the ground among those that were either found on the ground or in the business lists (concordance) as a measure of the overall level of agreement. For urban tracts, InfoUSA (28\%) showed higher concordance compared with D\&B (20\%). Overall, the agreement levels also were less than $30 \%$ in nonurban tracts in both databases (16\% for D\&B and $23 \%$ for InfoUSA). Combining the 2 business lists generated overall agreement levels of $24 \%$ and $22 \%$ for urban and nonurban tracts, respectively. However, none of the differences between the urban and nonurban tracts were statistically significant nor were there any statistically significant differences in concordance, overall agreement, across list type (Table 2).

In Table 3, we show whether detailed characteristics of PA facilities on the ground were different by whether those facilities were found in the business lists. In D\&B, in both urban and nonurban tracts, a higher proportion of PA facilities in the nonmatched group had a pool (28\% for urban and $26 \%$ for nonurban tracts) compared with the matched group ( $6 \%$ for urban and $0 \%$ for nonurban tracts). 
Table 3 Comparison of the Characteristics of Physical Activity Facilities Found on the Ground Survey by Listing Status

\begin{tabular}{|c|c|c|c|c|}
\hline & \multicolumn{2}{|c|}{ Urban } & \multicolumn{2}{|c|}{ Nonurban } \\
\hline & Nonmatch & Match & Nonmatch & Match \\
\hline \multicolumn{5}{|l|}{ D\&B } \\
\hline Charge a fee & 1.000 & 1.000 & 0.962 & 1.000 \\
\hline Require membership & 0.217 & 0.462 & 0.400 & 0.454 \\
\hline Offer instruction programs or lessons & 0.821 & 0.737 & 0.400 & 0.417 \\
\hline Have multiple cardio \& strength equipment & 0.280 & 0.462 & 0.304 & 0.333 \\
\hline Have a multipurpose room & 0.481 & 0.529 & 0.364 & 0.308 \\
\hline Have a gymnasium & 0.111 & 0.059 & 0.000 & 0.000 \\
\hline Have a court & 0.214 & 0.118 & 0.130 & 0.000 \\
\hline Have a pool & 0.276 & $0.059^{*}$ & 0.261 & $0.000 * *$ \\
\hline \multicolumn{5}{|l|}{ InfoUSA } \\
\hline Charge a fee & 1.000 & 1.000 & 1.000 & 0.929 \\
\hline Require membership & 0.286 & 0.333 & 0.417 & 0.417 \\
\hline Offer instruction programs or lessons & 0.821 & 0.737 & 0.522 & 0.214 \\
\hline Have multiple cardio \& strength equipment & 0.348 & 0.333 & 0.286 & 0.357 \\
\hline Have a multipurpose room & 0.480 & 0.526 & 0.286 & 0.429 \\
\hline Have a gymnasium & 0.148 & 0.000 & 0.000 & 0.000 \\
\hline Have a court & 0.222 & 0.111 & 0.136 & 0.000 \\
\hline Have a pool & 0.321 & $0.000 * *$ & 0.273 & $0.000 * *$ \\
\hline \multicolumn{5}{|l|}{ Combined } \\
\hline Charge a fee & 1.000 & 1.000 & 1.000 & 0.947 \\
\hline Require membership & 0.212 & 0.412 & 0.400 & 0.438 \\
\hline Offer instruction programs or lessons & 0.818 & 0.776 & 0.474 & 0.333 \\
\hline Have multiple cardio $\&$ strength equipment & 0.263 & 0.421 & 0.235 & 0.389 \\
\hline Have a multipurpose room & 0.429 & 0.565 & 0.250 & 0.421 \\
\hline Have a gymnasium & 0.136 & 0.045 & 0.000 & 0.000 \\
\hline Have a court & 0.227 & 0.130 & 0.176 & $0.000 *$ \\
\hline Have a pool & 0.348 & $0.143 * *$ & 0.353 & $0.000 * * *$ \\
\hline
\end{tabular}

Note. Reported numbers are proportions. PA facilities found on ground that were listed in a business list were classified as "match," and the remaining PA facilities that were not listed were classified as "nonmatch." * significant at the $10 \%$ level; ** significant at the $5 \%$ level; *** significant at the $1 \%$ level.

In InfoUSA no statistically significant differences were found in the characteristics of PA facilities on the ground in urban tracts compared with those listed in the commercial database except for that $32 \%$ of the nonmatched PA facilities had a pool whereas none of the matched PA facilities had a pool. PA facilities in nonurban tracts that had a pool were less likely to be listed in InfoUSA: none of the listed PA establishments had a pool, whereas pools were present in $27 \%$ of the PA establishments that were on the ground but not listed in InfoUSA (Table 3).

Significant differences in the characteristics of the PA facilities between the matched and the nonmatched groups persisted in the combined list. PA facilities in the matched group had a lower rate of having a pool $(4 \%)$ compared with PA establishments in the nonmatched group (35\%) in urban tracts. In addition, none of the matched PA establishments in the combined list had a court nor had a pool, whereas $18 \%$ and $35 \%$ of the nonmatched PA facilities had a court and a pool, respectively, in nonurban tracts (see Table 3).

Further, we reviewed the primary SIC codes for PA facilities that were not found on the ground but listed as such in each business list. For D\&B, there were 55 and 60 such PA facilities in urban and nonurban tracts, respectively, of which the 2 most frequent types were 
spas (9\%) and membership sports \& recreational clubs (9\%) in urban tracts, and public golf courses $(13 \%)$ and membership sports \& recreation clubs (15\%) in nonurban tracts. For InfoUSA, 21 and 31 PA facilities were not found on the ground but listed in the database in urban and nonurban tracts, respectively. The most frequent facility type listed in InfoUSA but not found on the ground in urban tracts was martial arts instruction facilities (24\%) followed by stables $(14 \%)$. Slightly less than one-quarter (23\%) of those facilities in nonurban tracts were health club studios and gymnasiums, and $16 \%$ were public golf courses (results not shown in Tables).

We also examined the type of PA facilities that were identified on the ground but not in the list, which were 21 and 21 facilities for InfoUSA and 22 and 18 for D\&B for urban and nonurban tracts, respectively. Of those, approximately $25 \%$ and $30 \%$ for nonurban and urban tracts, respectively, across the 2 business lists were local community-run recreation centers or pools, YMCAs or Jewish Community Centers (results not shown in Tables).

\section{Discussion}

We first showed that less than one-half $(41 \%$ for $D \& B$ and $39 \%$ for InfoUSA) of the PA establishments found on the ground were listed for the urban tracts, and between onethird and one-half were listed in either business list for the nonurban tracts (35\% for D\&B and $40 \%$ for InfoUSA). Sensitivity was improved by combining the 2 business lists; the sensitivity increased to $52 \%$ for both urban and nonurban tracts in the combined list. Second, we also found that approximately only one-quarter (23\% for nonurban and $29 \%$ for urban) of PA establishments listed were actually found on the ground in D\&B whereas $40 \%$ (nonurban tracts) and 50\% (urban tracts) of PA facilities were found on the ground in InfoUSA. Further, we found that PA establishments found on the ground that had a court or pool were less likely to be listed in either D\&B or InfoUSA as well as the combined list, particularly in the nonurban tracts. The overall concordance was poor in both D\&B (20\% and $16 \%$ for urban and nonurban tracts) and InfoUSA ( $28 \%$ and $25 \%$ ) and no statistically significant differences were found between the 2 lists. In sum, although InfoUSA overall showed significantly higher PPV than either D\&B or the combined list, we remain cautious in suggesting which dataset is more useful given that the differences of sensitivity and concordance between D\&B and InfoUSA were not statistically significant, and the sensitivity improved in the combined list.

The validation statistics from our results were comparable to the previous literature, although we could locate only 3 studies that validated secondary data sources for the PA environment. ${ }^{11-13}$ Paquet and colleagues validated 1 commercial database and a business list based on internet searches in $\mathbf{2 0 0 5}$ for food stores and PA facilities for 12 census tract boundaries in Montreal, Canada.
They reported 56\% for sensitivity, $63 \%$ for PPV, and concordance of $25 \%$." Boone and colleagues assessed 1 commercial database with commercial PA facilities in 80 census block groups in 1 urban and 1 nonurban community in the United States in 2005. They reported concordance of $39 \%$ and $46 \%$ for urban and nonurban communities, respectively, for all PA facility types combined. ${ }^{12}$ Lastly, Hoehner and Schootman ${ }^{15}$ compared D\&B and InfoUSA to examine agreement between the 2 sources in terms of the presence, locations, and characteristics of businesses for PA facilities as well as food stores and restaurants. Based on 4-digit SIC codes provided in each list, they matched businesses in each list in the St. Louis, Missouri area in 2007 by business name within specified distances. They reported that the level of agreement between the 2 secondary sources on commercial PA establishments was $63 \%$ and varied by population density in a given census-tract. However, this latter study did not validate each list based on actual field survey data. ${ }^{13}$

The quality of secondary data sources in evaluating PA environments is important to reach credible conclusions when using such databases. Accurately identifying PA facilities in a neighborhood using business lists may require more efforts compared with food stores and restaurants given the large variety of PA facility types with both public and private sources. ${ }^{11} \mathrm{~A}$ previous study that reported agreement between D\&B and InfoUSA of $63 \%$ for PA facilities, reported a higher level of agreement $(75 \%$ to $92 \%)$ for food stores and restaurants. ${ }^{15}$ Similarly, an international study also reported that all validation statistics including the percentage agreement, sensitivity, and PPV were all superior for food stores compared with PA-related businesses (65\% to $77 \%$ for food stores versus $25 \%$ to $42 \%$ for PA facilities for the percentage agreement; $66 \%$ to $84 \%$ for food stores and $33 \%$ to $56 \%$ for PA facilities for sensitivity; and, $58 \%$ to $98 \%$ for food stores and 50\% to 63\% for PA facilities for PPV). ${ }^{13}$

The results of this study are subject to a few limitations. First, our ground-truth survey data are based on 1 metropolitan urban area and surrounding nonurban area in the United States at a single point in time, and thus, whether the results of this study can be generalized across the United States is not known. Second, our field staff could only identify stand-alone facilities with clear PA indications although we performed a census for the sampled census tracts to identify PA facilities and collected their attributes inside each establishment. Therefore, if there were any individuals who were offering PA instruction in their home, for example, and listed themselves as a PA related business (not as an individual trainer) in a business list, such places were not included in our ground survey. Third, for this study we purchased the commercial business lists by SIC codes and did not provide any text strings to further obtain the list of PA facilities in those lists. Our findings indicated that governmental and nonprofit PA facilities that were found on 
the ground, particularly in nonurban tracts, were unlikely to be present in the business lists. This suggests that the business lists are less accurate at capturing information on governmental and nonprofit PA facilities in nonurban areas, or that these outlets are not recorded with PArelated SIC codes. Given that the prevalence of obesity is found to be significantly higher ${ }^{17-19}$ and PA is found to be significantly lower ${ }^{17.19 .20}$ in nonurban populations, it is particularly important to accurately identify whether arealevel disparities exist in PA resources including specific sports or activity features. However, we acknowledge that using text strings in addition to SIC codes could improve sensitivity. In addition, relying SIC codes in the commercial business lists to identify PA facilities restricted our understanding of the characteristics of listed facilities that were not discovered on the ground which may include closed businesses, misclassified listings, and corporate offices. Finally, our sample size is small; however, similar studies also had small sample sizes and our findings are similar to those found in another study in the United States. ${ }^{12}$ Despite these limitations, the current study built on the previous literature by validating the spatial patterning of PA establishments in 2 commercial secondary data sources in both urban and nonurban areas including information of the characteristics of the PA facilities surveyed on the ground.

\section{Conclusions}

Our study results indicate that the 2 secondary commercial business lists should be used with caution in assessing the built environment regarding PA facility availability. Combining the 2 business lists has an advantage in that researchers more accurately include what is actually on the ground when they use such lists to measure the PA environment. However, such improvement in the sensitivity is obtained at the expense of the deterioration of PPV and concordance. Therefore, the improved sensitivity in the combined lists is only useful when researchers can perform initial screening via phone to eliminate any closed PA facilities that remain in those lists. Such initial screening via phone would be a good alternative to the expense of ground truthing in a medium size study; but this may not be feasible for a large study.

\section{Acknowledgments}

We gratefully acknowledge research support from the Robert Wood Johnson Foundation through the Bridging the Gap program for the ImpacTeen project.

\section{References}

1. Flegal KM, Carroll MD, Ogden CL, Curtin LR. Prevalence and trends in obesity among US adults, 1999-2008. JAMA. 2010;303(3):235-241. PubMed
2. Ogden CL, Carroll MD, Curtin LR, Lamb MM, Flegal KM. Prevalence of high body mass index in US children and adolescents, 2007-2008. JAMA. 2010;303(3):242-249. PubMed doi:10.1001/jama.2009.2012

3. Gordon-Larsen P, Nelson MC, Page P, Popkin BM. Inequality in the built environment underlies key health disparities in physical activity and obesity. Pediatrics. 2006;117(2):417-424. PubMed doi:10.1542/peds.20050058

4. Pate RR, Pfeiffer KA, Trost SG, Ziegler P, Dowda M. Physical activity among children attending preschools. Pediatrics. 2004;1 14(5):1258-1263. PubMed doi:10.1542/ peds.2003-1088-L

5. Powell LM, Chaloupka FJ, Slater SJ, Johnston LD, O'Malley PM. The availability of local-area commercial physical activity-related facilities and physical activity among adolescents. Am J Prev Med. 2007;33(4, Supplement 1):S292-S300. PubMed doi:10.1016/j. amepre.2007.07.002

6. Norman GJ, Nutter SK, Ryan S, Sallis JF, Calfas KJ, Patrick K. Community design and access to recreational facilities as correlates of adolescent physical activity and body mass index. I Phys Act Health. 2006;3(Suppl 1):S118-S128.

7. Isgor Z, Powell LM. Availability of commercial physical activity facilities and physical activity outside of school among high school students. J Phys Act Health. 2010; in press. PubMed

8. Mota J, Almeida M, Santos P, Ribeiro JC. Perceived neighborhood environments and physical activity in adolescents. Prev Med. 2005;41 (5-6):834-836. PubMed doi: 10.1016/j. ypmed.2005.07.012

9. Scott MM, Evenson KR, Cohen DA, Cox CE. Comparing perceived and objectively measured access to recreational facilities as predictors of physical activity in adolescent girls. J Urban Health. 2007;84(3):346-359. PubMed doi: 10.1007/s 11524-007-9179-1

10. Cohen DA, Ashwood JS, Scott MM, et al. Public parks and physical activity among adolescent girls. Pediatrics. 2006;118(5):e1381-e1389. PubMed doi:10.1542/ peds.2006-1226

11. Wolch J, Jerrett M, Reynolds K ... Berhane K. Childhood obesity and proximity to urban parks and recreational resources: A longitudinal cohort study. Health Place. 2010; in press. PubMed

12. Berkey CS, Rockett HR, Field AE, et al. Activity, dietary intake, and weight changes in a longitudinal study of preadolescent and adolescent boys and girls. Pediatrics. 2000;105(4):E56. PubMed doi:10.1542/peds.105.4.e56

13. Paquet C, Daniel M, Kestens Y, Leger K, Gauvin L. Field validation of listings of food stores and commercial physical activity establishments from secondary data. Int J Behav Nutr Phys Act. 2008;5(1):58. PubMed doi:10.1186/1479-5868-5-58

14. Boone JE, Gordon-Larsen P, Stewart JD, Popkin BM. Validation of a GIS Facilities Database: Quantification and Implications of Error. Ann Epidemiol. 2008;18:371-377. PubMed doi:10.1016/j.annepidem.2007.11.008

15. Hoehner C, Schootman M. Concordance of commercial data sources for neighborhood-effects studies. J Urban Health. 2010;87(4):713-725. PubMed doi:10.1007/ s! 1524-010-9458-0 
16. Powell LM, Han E, Khan T, Quinn C, Pugach O, Gibbs $\mathrm{K}, \ldots$ Chaloupka $\mathrm{F}$. Field validation of secondary commercial data sources on the retail food outlet environment in the U.S. Health Place. 2011 ; in press.

17. Joens-Matre RR, Welk GJ, Calabro MA, Russell DW, Nicklay E, Hensley LD. Rural-urban differences in physical activity, physical fitness, and overweight prevalence of children. J Rural Health. 2008;24(1):49-54. PubMed doi: $10.1111 / \mathrm{j} .1748-0361.2008 .00136 . x$

18. Liu J, Bennett KJ, Harun N, Probst JC. Urban-rural differences in overweight status and physical inactivity among US Children aged 10-17 years. J Rural Health. 2008;24(4):407-415. PubMed doi:10.1111/j.1748$0361.2008 .00188 . x$
19. Patterson PD, Moore CG, Probst JC. Obesity and physical activity in rural America. $J$ Rural Health. 2004;20(2):151156. PubMed doi: 10.1111/j.1748-0361.2004.tb00022.x

20. Singh G, Kogan M, Siahpush M, van Dyck P. Independent and joint effects of socioeconomic, behavioral, and neighborhood characteristics on physical inactivity and activity levels among US children and adolescents. $J$ Community Health. 2008;33(4):206-216. PubMed doi:10.1007/ s10900-008-9094-8 
Copyright of Journal of Physical Activity \& Health is the property of Human Kinetics Publishers, Inc. and its content may not be copied or emailed to multiple sites or posted to a listserv without the copyright holder's express written permission. However, users may print, download, or email articles for individual use. 